American Journal of Agricultural and Biological Sciences 5 (1): 15-19, 2010

ISSN 1557-4989

(C) 2010 Science Publications

\title{
Soil Compaction and Oil Palm (Elaeis guineensis) Yield in a Clay Textured Soil
}

\author{
${ }^{1}$ Zuraidah Yahya, ${ }^{2}$ Aminuddin Husin, ${ }^{2}$ Jamal Talib, ${ }^{3}$ Jamarei Othman, \\ ${ }^{4}$ Osumanu Haruna Ahmed and ${ }^{5}$ Mohamadu Boyie Jalloh \\ ${ }^{1}$ Biology Division, Malaysian Palm Oil Board, No. 6 Persiaran Institusi, BB Bangi, 43000 Kajang \\ ${ }^{2}$ Department of Land Management, Faculty of Agriculture, University Putra Malaysia, \\ 43400 UPM Serdang, Malaysia \\ ${ }^{3}$ Department of Agricultural and Biological Engineering, Faculty of Engineering, \\ University Putra Malaysia, 43400 UPM Serdang, Malaysia \\ ${ }^{4}$ Department of Crop Science, Faculty of Agriculture and Food Science, \\ University Putra Malaysia, Bintulu Campus, Sarawak, 97008 Bintulu, Sarawak, Malaysia \\ ${ }^{5}$ Crop Production Programme, School of Sustainable Agriculture, University Malaysia Sabah, \\ Locked Bag 2073, 88999 Kota Kinabalu, Sabah, Malaysia
}

\begin{abstract}
Problem statement: The impacts of soil compaction on crop yields have been studied extensively by soil scientists due to declining soil productivity associated with mechanisation. However, a relationship between machine-induced soil compaction and oil palm (Elaeis guineensis) yield is unclear. Therefore, the objectives of this study were to determine the effects of mechanization on soil physical properties and the influence on oil palm yield. Approach: The palms were planted in Bernam series soil which is clay textured. Compaction treatments were imposed for 6 consecutive years. Comparisons were made between the effects of soil compaction caused by different trailer weights and monthly transportation frequency. Results: The results showed a beneficial effect of soil compaction on the oil palm yield. It significantly increased the yield with increased mean soil bulk density. The transportation frequency played a greater role than the trailer weight. After six years of soil compaction, there was a positive relationship between mean soil bulk density, porosity and oil palm yield. Conclusion: Thus compaction may not often be a problem.
\end{abstract}

Key words: Soil compaction, oil palm, transportation frequency, trailer weight, soil physical properties

\section{INTRODUCTION}

The oil palm, Elaeis guineensis Jacq, is the most important industrial crop in Malaysia and remains as the 'golden crop' which contributes to the global oils and fats trade. It is not only supplying oil to the food industry but also to the oleochemical and biocomposites industries. Oil palm plantations have always been a labor intensive industry. The rapid development of the Malaysian economy has created competition for labor that has resulted in an acute labor shortage in the oil palm industry. Hence, the use of machines in the oil palm industry is more extensive to reduce the dependence on labor as well as to turn the industry into a more mechanized, high technology, well-managed and globally competitive industry. Various types of imported, locally fabricated or adoptive technology machinery and equipment have been introduced to the plantations either to assist workers or to increase productivity (Kamarudzaman and Mohd Hashim, 1998). It is now generally accepted that sustaining the industry will partly depend on mechanization which is now widely adopted in oil palm plantations. A major achievement in reducing labor to land ratio has resulted from mechanized in-field FFB collection, mechanical spreading of fertilizer and mist blower method of weeding. A study (Yusof and Ahmad, 1998) reported that adoption of mechanization by an oil palm plantation has shown a decrease of about $30 \%$ in labor requirement with a $30 \%$ increase in productivity.

One of the main concerns regarding mechanization in oil palm plantations is soil compaction caused by repeated traffic on the harvesting paths by the machines which affects soil health. Compaction changes

Corresponding Author: Osumanu Haruna Ahmed, Department of Crop Science, Faculty of Agriculture and Food Sciences, University Putra Malaysia Bintulu Campus, Sarawak, Malaysia Tel: +6086855406 Fax: +608685415 
structural characteristics and functions of soil, which could have an effect on yield. This can result in both desirable and undesirable effects on plant growth, depending on the severity of the compaction (Raper and Kirby, 2006; Mari and Changying, 2008). The degree of compaction caused by vehicle traffic is dependent on two main factors. First, the contact pressure of the vehicle which is determined by the overall weight of the vehicle. The greater the contact pressure or more frequently the vehicle passes over a particular area in the field, the greater and deeper will be the resulting compaction. Second, is the soil moisture content at the time of traffic. The greatest amount of compaction occurs when the soil is wet (Hamza and Anderson, 2005). However, as soil water content increases, a point is reached where most pore spaces in the soil are filled with water. Water cannot be compressed, therefore a very wet soil will not compact as much as a moderately moist soil. Other factors that influence soil compaction include soil type, type of crop grown and weather.

Most reports have indicated the causes of soil compaction and its detrimental effects on crop production. Reduced porosity and aeration, increased resistance to root penetration, limited water and nutrient availability to plants due to compaction are major constraints to plant growth and yields in many soils. The inability of roots to penetrate compacted soil layers will result in decreased plant productivity. A reduction in yield or yield potential is the most significant practical effect that soil compaction has on crops (Coder, 2000; DeJong-Hughes et al., 2001; Hanna and Kaisi, 2002; Abu-Hamdeh, 2003; Duiker, 2004; Ponder, 2004; Zhang et al., 2006).

Soil compaction is a significant problem in soils planted with oil palm as heavy machinery are used in harvesting and most cultural practices which could cause soil degradation. There is an increasing concern about the long term effects of soil compaction due to the increasing weight of agricultural equipment. Being a perennial crop, the oil palm produces fruit bunches throughout the year. The oil palm takes three years to reach maturity after field planting and continues producing fruits for up to 25 years when replanting is normally recommended because the palms are too tall for easy harvesting. Therefore the soil should be protected during all management activities associated with production as equipment used could have negative effects on the soil properties. Machines used in oil palm plantations should be of appropriate size and weight according to the soil type for minimizing soil compaction.

The objective of this study was to determine the effect of trailer weight and transportation frequency on soil physical properties and their influence on oil palm yield.

\section{MATERIALS AND METHODS}

The study was conducted on a 22 hectares oil palm plantation in Melentang Estate, Bagan Datok, Perak, Malaysia. The soil is a flat coastal terrain of Bernam series (Paramananthan, 2000) and clay texture (50\% clay, $32 \%$ silt and $18 \%$ sand). The soil bulk density, particle density and porosity were 0.8 and $2.45 \mathrm{~g} \mathrm{~cm}^{-3}$ and $67 \%$ respectively. The average rainfall was 1400 $\mathrm{mm}$ a year and $115 \mathrm{~mm}$ a month. The palm crop in the trial area was planted in 1996 using GH300 D $\times$ P materials with a planting density of 148 palms per hectare and the compaction trial started in 2002 when the palms were about 7 years old. All field management practices at the trial site, such as fertilizer application, FFB evacuation and weeding were carried out manually.

The treatments were a combination of three trailer weights and four transportation frequencies. The three trailer weights were 0T (tractor without trailer), $2 \mathrm{~T}$ (tractor with 2 tonnes trailer weight) and 4T (tractor with 4 tonnes trailer weight). The four transportation frequencies were 0 (control), 1,2 and 3 rounds per month. There was no vehicle traffic in the control plots. The experimental design was a randomized complete block design in factorial treatment combination (3 trailer weights $\times 4$ transport frequencies) each replicated five times.

A split tube sampler with sampling rings of $5 \mathrm{~cm}$ height and diameter were used. The sampling depths were $0-10,10-20$ and $20-30 \mathrm{~cm}$. Soil samplings were done twice a year for determination of soil bulk density, porosity and available water. Soil samples were taken from 3 locations in the treated plots, 2 locations from the 'harvesting paths' (under and between the wheels tracks) and one from the 'frond pile areas'. For the control plots, soil sampling was done at 2 locations i.e. one from the 'harvesting paths' and one from the 'frond pile areas'. Soil bulk density was determined using the core method (Blake and Hartge, 1986) and soil porosity was derived mathematically from bulk and particle density measurements. The soil moisture properties were determined using ceramic plates (Townend et al., 2001).

Yield records were taken by estate workers at each harvesting round which was every 10-12 days. The number and weight of the fresh fruit bunches harvested were recorded from the 16 recording palms per plot. These values were then extrapolated to tonnes of Fresh Fruit Bunch (FFB) per hectare per year. 
Although the compaction treatment started in 2002, the data used for statistical analysis were those collected between the years 2006 and 2008.

\section{RESULTS}

Six years of continuous compaction resulted in an inverse relationship between Bulk Density (BD) and porosity. Increase in trailer weight resulted in an increase in mean soil BD and a decrease in total porosity decreased. Soil BD increased by about $10.5 \%$ and there was significant total porosity reduction $(5.3 \%)$ for the 4 tonnes trailer weight treatment compared to the control. However the three trailer weight treatments resulted in significant effects on the mean soil BD and total porosity only for 3 rounds per month Transportation Frequency (TF). Both 0 and 2 tonnes trailer weight treatments showed similar effects on mean soil BD and porosity for 1 and 2 rounds per month but significantly higher at 3 rounds per month TFs. For the 4 tonnes trailer weight, the mean soil BD was significantly increased and porosity decreased with increasing TF (Fig. 1). This indicates that the TF for heavier machines contribute significantly to soil compaction. Soil BD was affected by the compaction only within the first $0-10 \mathrm{~cm}$ depth for locations under and between the tracks. Deeper soil (below the top 10 $\mathrm{cm}$ ) was not affected by the treatments. Although the mean soil BD increased, the values were still below the root-limiting critical range which is about $1.39 \mathrm{~g} \mathrm{~cm}^{-3}$ for clay soil.

The results showed that increased mean soil BD and reduced porosity were beneficial to the oil palm. The mean Fresh Fruit Bunch (FFB) yield and the number of bunches produced in the treated plots were about $12 \%$ higher compared to the control. The trailer weight treatments did not have any significant effect on the FFB yield but there was significant increase in FFB yield with increasing TF. The three rounds per month TF resulted in the highest FFB yield for all treatment combinations (Fig. 2).

The compaction treatments had no significant effect on mean bunch number per palm and mean bunch weight as shown in Fig. 3a and b respectively, but palms planted on plots subjected to higher transportation frequency resulted in higher bunch numbers.

The results of the mean soil Available Water (AW) as shown in Fig. 4 were unaffected by different trailer loads and transportation frequency. However, AW was higher at sampling locations under the tyre tracks and between the two tracks compared to the frond pile paths.

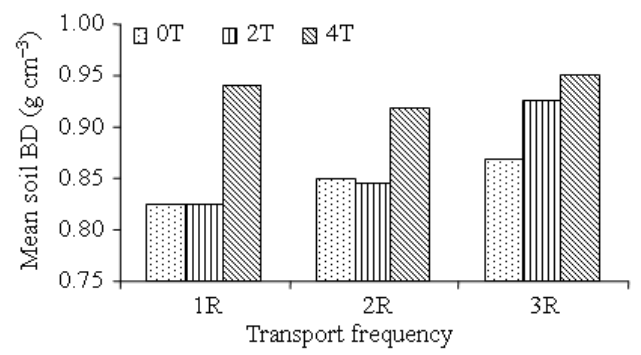

Fig. 1: Effect of increasing transportation frequency of different trailer weights

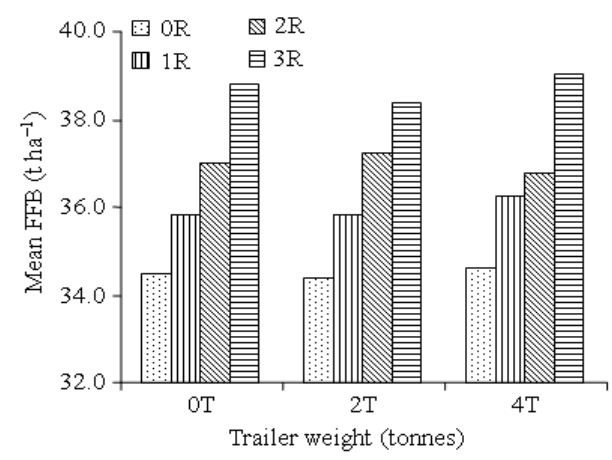

Fig. 2: Mean oil palm fresh fruit bunch yield in response to different trailer weight and transportation frequency

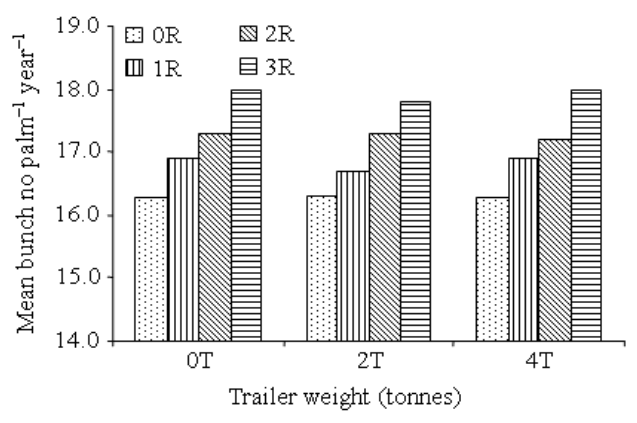

Fig. 3a: Mean bunch number palm ${ }^{-1}$ year $^{-1}$

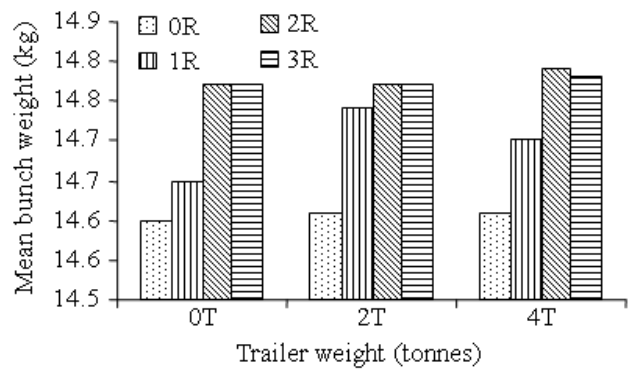

Fig. 3b: Mean oil palm bunch weight 


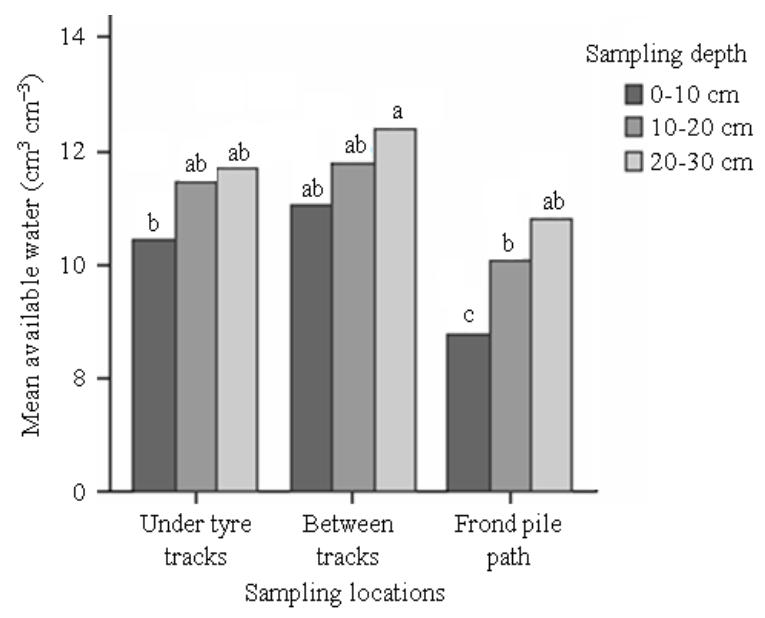

Fig. 4: Mean soil available water at different sampling locations and depths

Higher AW was also observed at lower soil depths for all sampling locations. Higher soil BDs in the treatment plots may have enhanced the soil's ability to retain water which contributed to higher yield. This could be attributed to improved nutrient uptake associated with higher AW in the treatment plots.. Optimal soil condition exist when there are enough large pores to transmit water readily s well as adequate small pores to retain and store water which is the transport medium of nutrients available for better plant growth. This condition also increases the nutrient mobility rates to roots by diffusion and mass flow in the transpiration stream.

\section{DISCUSSION}

Soil compaction impacts crop yields and soil productivity in various ways. It is widely accepted that Soil Compaction (SC) is detrimental to crops. Soil compaction from heavy equipment can alter many characteristics of soil and plant responses may be correlated with these alterations. It could also limit plant growth depending on the stage of development and prevailing environmental conditions.

For growing plants, pore size is more important than total pore space and larger void space could lead to poor root contact with the surrounding soil. Therefore, some degree of compaction is desirable to provide a suitable soil density for plant growth in low bulk density soils. Increase in soil bulk density and reduced porosity could provide better root contact with surrounding soil and enhance nutrient uptake which would result in better oil palm yield.
The overall primary effect of soil compaction on plant growth is to a large extent associated more directly with water than with any other factor. The degree of soil wetness changes the proportional relationships of air to water which affects the rest of the soil's physical properties, such as bulk density, infiltration rate and soil elasticity (Mahdi Al-Kaisi, 2007). As soil bulk density increases, porosity will decrease as a result of reduction in macropores size. However, this would then increase the amount of micropores which will retain more water and hold moisture as well as ionized minerals or nutrients more effectively in the soil.

Soil compaction also affects water movement. It has been reported (Andrian et al., 2005) that compaction increased Available Water (AWC) content at 0-10 cm depth by $24-59 \%$ compared to non-compacted soil. At both $0-10$ and 10-20 cm depths of the non-compacted soil, AWC was lower compared to the compacted soil. On highly fertile soils, the effect of compaction on yields was due to moisture and aeration effects. However, a plant grown in compacted soils can respond normally as long as all of its requirements are satisfied. Although there is ample evidence supporting the notion of reduction in plant growth caused by soil compaction; this is not always the case. The results of a study on compaction effects on 4 years old ponderosa pine varied with soil texture and soil water (Ponder, 2004). Much of the improved growth was attributed to better soil physical changes that caused better soil moisture conditions for growth and the results showed that compaction had a positive effect on shortleaf pine growth.

Although it is widely reported that soil compaction reduces oil palm yield, the results of this study are a contrary. An increase in FFB yield was also reported (Haniff et al., 2005). It appears that the effect of transportation frequency was more significant than trailer weight in influencing palm yield.

\section{CONCLUSION}

The 3 rounds per month transportation frequency for the 3 trailer weights significantly increased the soil bulk density and reduced porosity. With increasing loads and number of passes, the total FFB yield increased significantly by about $12 \%$ compared to the control. These results indicate that the oil palm did not suffer yield depression from the six years of surface compaction treatments in Bernam series soil. Unexpectedly, the oil palm yield was better following the compaction treatments. The positive relationship between mean soil bulk density, porosity and oil palm 
yield shows that compaction may not always be deleterious to palm production.

\section{ACKNOWLEDGEMENT}

The researchers acknowledge the financial support of this research through the Intensive Research in Priority Areas (IRPA) grant from the Ministry of Higher Education, Malaysia.

\section{REFERENCES}

Abu-Hamdeh, N.H., 2003. Compaction and subsoiling effects on corn growth and bulk density. Soil Sci. Soc. Am. J., 67: 1213-1219. http://soil.scijournals.org/cgi/reprint/67/4/1213

Andrian, A, A.T. Thomas, E.M. Richard, W.A. Harry and L.F. Barry, 2005. Ground-based forest harvesting effects on soil physical properties and douglas-fir growth. Soil Sci. Soc. Am. J., 69: 1822-1832. DOI: 10.2136/sssaj2004.0331

Blake, G.R. and K.H. Hartge, 1986. Methods of soil analysis. Part 1. Physical and mineralogical Methods. Second edition. American society of agronomy and Soil science of America. ISBN: 0891180885 (pt. 1), pp: 364-366.

Coder, K.D., 2000. Soil compaction Impacts on Tree Roots. University of Georgia. http://warnell.forestry.uga.edu/warnell/service/libra ry/for00-008/for00-008.pdf

DeJong-Hughes, J., J.F. Moncrief, W.B. Vorhees and J.B. Swan, 2001. Soil compaction: Causes, effects and control. Communication and Educational Technology Services, University of Minnesota Extension Service.

http://www.extension.umn.edu/distribution/cropsys tems/DC3115.html

Duiker, S.W., 2004. Effects of soil compaction. Pennsylvania State University, CAS, ARCE. http://pubs.cas.psu.edu/freepubs/pdfs/uc188.pdf

Hamza, M.A. and W.K. Anderson, 2005. Soil compaction in cropping system. A review of the nature, causes and possible solutions. Soil Tillage Res., 82: 121-145. DOI: 10.1016/j.still.2004.08.009

Hanna, M. and M.A. Kaisi, 2002. Soil compaction may be cutting into your yield. Integ. Crop Manage., IC-488: 135-136.

http://www.ipm.iastate.edu/ipm/icm/2002/7-82002/soilcompact.html

Haniff M.H., A.S. Rahim, O. Wahid, A.M. Tarmizi and M.M. Faiz, 2005. Effects of soil compaction on oil palm productivity. Proceedings of the PIPOC 2005 International Palm Oil Congress, pp: 469-475.
Kamarudzaman, A. and T. Mohd Hashim, 1998. Technical and social issues of mechanization in oil palm plantation industry. Proceedings of the National Seminar on Mechanization in Oil Palm Plantation, Towards Improving Productivity Through Mechanization, pp: 39-45.

Mahdi Al-Kaisi, 2007. Wet Soils and Potential Compaction. Integ. Crop Manage., 498: 106. http://www.ipm.iastate.edu/ipm/icm/2007/49/moisture.html

Mari, G.R. and Ji. Changying, 2008. Influence of agricultural machinery on soil compaction patterns, root development and plant growth, overview. Am. Eurasian J. Agric. Environ. Sci., 3: 49-62. http://www.idosi.org/aejaes/jaes3(1)/8.pdf

Paramananthan, S., 2000. Soils of Malaysia: Their characteristics and identification. http://www.cababstractsplus.org/abstracts/Abstract. aspx?AcNo=20023037594

Ponder, F., 2004. Soil compaction affects growth of young shortleaf pine following litter removal and weed control in the Missouri Ozarks. Proceedings of the 14th Central Hardwoods Forest Conference GTR-NE-316, pp: 255-264. http://www.fs.fed.us/ne/newtown_square/publicati ons/technical_reports/pdfs/2004/ne_gtr316.pdf

Raper, R.L. and J.M. Kirby, 2006. Soil compaction: How to do it, undo it, or avoid doing it. Proceedings of the Agricultural Equipment Technology Conference, ASABE, pp: 1-11. http://asae.frymulti.com/data/pdf/6/sc2006/Lecture Series2006.pdf

Townend, J., M.J. Reeve and A. Carter, 2001. Water Release Characteristics. Soil and Environmental Analysis. Physical Methods. 2nd Edn., Revised and Expanded, ISBN: 0824704142, pp: 111.

Yusof, B. and H. Ahmad, 1998. Role of mechanization in the oil palm industry. Proceedings of the National Seminar on Mechanization in Oil Palm Plantation, Towards Improving Productivity Through Mechanization, pp: 25-31.

Zhang, X.Y., R.M. Cruse, Y.Y. Sui and Z. Jhao, 2006. Soil compaction induced by small tractor traffic in Northeast China. Soil Sci. Soc. Am. J., 70: 613-619 DOI: $10.2136 /$ sssaj2005.0121 